\title{
Cálculo de índice orçamentário das instalações hidráulicas de uma construção, em função da área construída e do INCC
}

\author{
Denise Silva Alves', Tânia Cristina Macena', Marcelo Tsuyoshi Haraguchi', Fernando Ernesto Ucker', \\ Pedro Daniel da Cunha Kemerich², Wilian Fernando Borba ${ }^{3}$

\footnotetext{
' Laboratório de Planejamento e Monitoramento Ambiental - LPMA/UFSM, Curso de Engenharia Ambiental da Universidade Federal de Santa Maria/CESNORS, Frederico Westphalen, Brasil.

${ }^{2}$ Coordenador do Curso de Engenharia Ambiental da Universidade Federal de Santa Maria/CESNORS, Frederico Westphalen, Brasil.

3 Técnico em Agropecuária, Aluno de Graduação do Curso de Engenharia Ambiental, Universidade Federal de Santa Maria, Santa Maria, Brasil.
}

\section{Resumo}

O Orçamento pode ser definido como a previsão do custo de uma obra (insumos e serviços) antes de sua execução. Para elaborar um orçamento, é necessário desenvolver uma sequência de tarefas sucessivas (levantar e conhecer com profundidade o consumo de materiais em cada um dos serviços a serem realizados, a quantidade de mão de obra, a incidência das leis trabalhistas, o tempo de uso dos equipamentos, os custos financeiros decorrentes, os custos administrativos (indiretos) e a carga tributária que irá pesar sobre os serviços). Um orçamento pode resultar em duas realidades opostas, quando mal elaborado e sem critérios definidos, traz prejuízos e quando bem elaborado com os devidos critérios, garante o lucro e a sobrevivência das empresas. O trabalho apresenta o desenvolvimento de um índice, obtido a partir de uma planilha orçamentária que exprime o valor global para a execução das instalações hidráulicas de uma obra, (resultado da compatibilização entre planilha de levantamento de quantitativo e planilha de custo unitário) em relação à sua área de construção. O empreendimento considerado é destinado ao uso comercial, possui 03 pavimentos e 4 (quatro) salas destinadas à locação. O índice de atualização será o INCC - Índice Nacional de Custo da Construção Civil, com data base no mês de Junho de 2012. Esse índice torna possível a obtenção de um valor próximo do real por estimar os custos de instalação hidráulica de um empreendimento similar, minimizando o tempo de execução de um orçamento.

Palavras-chave: Orçamento, Planilha Orçamentária, Custo, Índice, Instalações Hidráulicas.

\begin{abstract}
The budget can be defined as the expected cost of a work (inputs and services) before its execution. To draw up a budget, it's necessary to develop a sequence of consecutive tasks (to lift and meet deeply the spend of materials and services to be perform, the labor's amount, the incidence of labor law, time of the equipaments, the financial and indirect administrative costs and the tax burden that will weigh on services. A budget can result in two opposing realities, when it is poorly designed, without defined criteria, it can causes damages, otherwise, it ensures profitability and the corporate survival. This study presents the index development derived from a spreadsheet budget that expresses the overall value for the execution of a plumbing work (results of compatibility between the quantity of materials and labour worksheet and unit cost spreadsheet) relative to its construction area. The project considered here is for comercial use, it has three floors an four offices for rental. This index makes possible to obtain a value close to estimate the real costs of a hydraulic system for a similar project, minimizing the execution budget time.
\end{abstract}

Keywords: Budget, budget worksheet, cost, index, hydraulic installations 


\section{INTRODUÇÃO}

A recessão econômica mundial, em 2008 e em 2009, responsável por uma crise imobiliária anunciada nos EUA, não causou impactos significativos nos países em desenvolvimento como o Brasil, pois aqui houve medidas que foram adotadas tais como: o incentivo do Programa de Aceleração do Crescimento (PAC) relacionado à construção civil e infraestrutura, o programa Minha Casa Minha Vida, com a expansão do crédito para habitação, e a desoneração tributária de alguns materiais da construção civil.

Com isso, o Brasil vem vivenciando uma expansão no ramo da Construção Civil onde, cada vez mais, obras são construídas com um cronograma de execução de curtos prazos, alta exigência de qualidade, metas em termos de custo, alto faturamento e desempenho gerencial dentro das empresas.

Para o sucesso de um empreendimento, é fundamental o estudo de viabilidade econômica. Com as novas dimensões do mercado e das diretrizes da globalização, existe a necessidade de dominar com segurança as finanças do empreendimento.

Orçar é quantificar insumos, mão de obra e equipamentos necessários à realização de uma obra ou serviço, bem como os respectivos custos e o tempo de duração dos mesmos (LOPES et al., 2003). Nos orçamentos, todos os custos se referem ao tempo presente, isto é, materiais, mão de obra e insumos cotados para pagamento à vista (AGETOP, 2006). Isso demanda uma metodologia capaz de gerar informações de qualidade, de relevância e em tempo hábil para as tomadas de decisão.

Entende-se que, para a sobrevivência e permanência competitiva das empresas no mercado, é necessário que estas integrem o processo de gestão da empresa ao processo de gestão de custos (CORDEIRO, 2007).

Existem vários tipos de orçamento e o padrão escolhido depende da finalidade da estimativa e da disponibilidade de dados. Se há interesse em obter uma estimativa rápida ou baseada apenas na concepção inicial da obra ou em um anteprojeto, o tipo mais indicado é o paramétrico. Para as incorporações em condomínio, a lei exige o registro de informações, em cartório, seguindo um procedimento padronizado, de acordo com a norma NBR 12721 (ABNT, 1999).

Segundo Cordeiro (2007), para executar um orçamento, a construtora deve seguir processos definidos, conhecer suas possibilidades e limitações técnicas e deve saber unir materiais e sistemas construtivos, para ter um produto final de boa qualidade. Cada item deve ter uma composição planejada, que respeite a cultura da empresa construtora, seus procedimentos, capacidade financeira e organizacional, para tornar aquele orçamento exequível. Seja um empreendimento com fins lucrativos ou não, a construção implica gastos consideráveis e, por isso mesmo, devem ser determinados, já que, em função de seu valor, o empreendimento será viável ou não.

Este é um dos passos que consomem maior tempo e custo do administrador ou planejador, sendo que a disponibilidade de dados, particularmente no setor da construção civil, é muito pequena.

O ideal neste levantamento de informações, é que a empresa obtenha seus próprios índices, de maneira a poder ter maior controle e confiabilidade sobre as variáveis que influenciam seu custo (OTERO, 2002).

$\mathrm{Na}$ busca pela diminuição do tempo de execução de um orçamento, com vista na minimização dos recursos e prazos, coloca-se como uma alternativa para o levantamento de custos na construção de uma obra, com uma metodologia que apresente de forma precisa um índice estimado a partir de uma área para as Instalações Hidráulicas, podendo substituir os orçamentos detalhados, em vários momentos, de forma eficiente e decisiva.

Por isso, o objetivo deste trabalho foi realizar um estudo de caso para a região metropolitana de Goiânia-GO, a partir dos levantamentos quantitativos de um empreendimento comercial com 03 pavimentos de área útil, com base em preços de insumos e serviços pesquisados no âmbito local. Este estudo poderá abrir caminhos para novas pesquisas e, assim, aumentar as possibilidades para estimar outros padrões de construções e se estender para outras regiões.

\section{MATERIAL E MÉTODOS}

Este estudo de caso buscou obtenção de um índice para cálculo do custo de Instalações hidrossanitárias que se condicionam a construções com características próximas às do empreendimento objeto de estudo. As características do empreendimento considerado (para uso comercial, com até 03 pavimentos de área útil, dentro da região metropolitana de Goiânia - GO) deverão ser levadas em consideração, para que seja possível a utilização do mesmo índice, com a máxima redução dos erros críticos de uma estimativa.

A partir desta análise, outros estudos poderão ser futuramente desenvolvidos, para construções com diferentes tipos de características como, por exemplo, em residenciais verticais ou horizontais, de múltiplos pavimentos, ou em outras regiões (cidades e estados).

Para o projeto considerado, temos as seguintes condições de um empreendimento comercial para fins de locação, com 03 pavimentos distintos: subsolo, térreo, pavimento superior, além da cobertura/ barrilete, situado no setor sul da cidade de Goiânia - GO. A área do subsolo é destinada a vagas de estacionamento, 
com pé direito de $3,80 \mathrm{~m}$. O térreo é destinado a duas locações distintas, sala 1 e sala 2 par fins comerciais, desde que não voltada para o comércio de alimentos. O pé direito deste pavimento é de $3,80 \mathrm{~m}$. O pavimento superior é composto de duas salas distintas para locação, seguindo a mesma característica da sala do pavimento térreo, apresentando pé direito de $3,00 \mathrm{~m}$. Na cobertura em laje impermeabilizada, localiza-se o barrilete para abastecimento do prédio, com 08 caixas em fibra de vidro, com 20.000 litros de capacidade cada.

As 03 salas comerciais ( 01 no pavimento térreo e 02 no pavimento superior) apresentam 02 banheiros do tipo lavabo (masculino e feminino), com uma bacia sanitária e lavatório, uma copa para serviço, com 01 cuba em aço inox embutida em bancada em cada sala. A sala 1 do térreo tem 05 banheiros do tipo lavabo, com uma bacia sanitária e lavatório, e uma copa para serviço, com 01 cuba em aço inox embutida em bancada.

O projeto hidrossanitário (Anexo 08) considerado é uma versão com suas devidas aprovações e com seus devidos detalhamentos, conforme segue abaixo:

i. Planta baixa água fria: subsolo, térreo, superior e cobertura;

ii. Planta baixa esgoto: térreo e superior; iii. Planta baixa água pluvial: térreo, superior e cobertura;

iv. Isométrico: água fria.

\section{RESULTADOS E DISCUSSÕES}

\section{I Planilha de Levantamento por Pavimento}

Esta etapa da elaboração do orçamento se resumiu a levantar, de forma técnica, as quantidades de serviços informados nas especificações e estimar os serviços que não foram devidamente especificados, mas que são essenciais e necessários à obra.

A planilha de levantamento por pavimento foi desenvolvida a partir do quantitativo de peças e tubulações apresentadas no projeto de instalação hidrossanitária, do empreendimento em análise. A planilha é composta de 05 (cinco) colunas contendo as seguintes informações:

1) Rede: especifica o tipo de instalação que está sendo levantada (hidráulica, esgoto ou pluvial)

2) Pavimento: A localização do levantamento considerado nas diversas alturas da edificação (subsolo, térreo, superior ou cobertura)

3) Tipo: apresenta os tipos de levantamento que estão sendo considerados (caixa de passagem, acessórios, conexões e tubulações em PVC).

4) Item: indica a descrição (nome) dos insumos que estão sendo levantados no levantamento;

5) Quantidade: apresenta o número de repetições de cada item que consta no projeto.

\subsection{Planilha de levantamento resumo}

A planilha resumo apresenta as quantidades totais da planilha de levantamento quantitativo, por pavimento, dos insumos levantados em projeto.

A planilha é composta de 03 (três) colunas, contendo as seguintes informações:

1) Rede: especifica o tipo de instalação que está sendo considerada (hidráulica, esgoto ou pluvial);

2) Item: indica a descrição (nome) dos insumos que estão sendo levantados no levantamento;

3) Quantidade: apresenta o número de repetições de cada item que consta no projeto.

\subsection{Planilha de composição de preços unitários}

Cada composição foi elaborada após a realização da pesquisa de preço dos insumos no mercado local e após o levantamento das quantidades dos materiais. Nesta planilha, é especificado o custo unitário dos serviços que correspondem à instalação dos materiais a serem utilizados na obra. Para a composição deste custo, são considerados os consumos e preços de mão de obra, encargos sociais trabalhistas, materiais específicos e complementares, consumos específicos durante a execução da obra, entre outros. Os índices de consumo de mão-de-obra e material por unidade de serviço foram obtidos de acordo com a Tabela de Composições de Preços para Orçamentos (TCPO - $13^{\circ}$ Edição - Editora Pini). Cada composição foi lançada de acordo com o apresentado na coluna Item e Quantidade da Planilha de Levantamento Quantitativo Resumo.

A planilha é composta de 29 (vinte e nove) colunas, contendo as seguintes informações:

1) Instalações: especifica o tipo de instalação que está sendo considerada (hidráulica, esgoto ou pluvial).

2) Descrição: indica a descrição (nome) dos insumos que foram levantados em projeto e precisam ser calculados para a apresentação do custo total.

3) Unidade: indica a mensuração (fator de medida) de cada composição.

4) Quantidade: apresenta o número de repetições de cada item que consta no projeto. 5) Materiais Lista: apresenta o consumo (quantidade a ser utilizada do insumo que dá o nome à composição), custo unitário (custo de cotação feito no mês de Junho de 2012, nas lojas do ramo na cidade de 
Goiânia-Go) e custo reajustado pelo INCC atual (índice econômico com reajuste a partir do mês de junho/2012).

6) Materiais Complementares: apresenta a listagem de materiais que complementam a instalação do material principal (que dá nome à composição) com o seu custo unitário (custo de cotação feito no mês de Junho de 2012, nas lojas do ramo na cidade de Goiânia-Go).

7) Mão de obra: Os valores de mão-de-obra do estudo foram conseguidos diretamente no sindicato dos trabalhadores da construção civil (Sinduscon Goiás 2012 - Anexo), na Planilha de Pisos Salariais dos Trabalhadores da Construção Civil em Goiás, de 01 de maio de 2012 a 30 de abril de 2013 . Assim, têm-se:

a) Encanador: $R \$ 4,82 / \mathrm{h}$;

b) Ajudante: $\mathrm{R} \$ 2,89 / \mathrm{h}$.

8) As leis sociais trabalhistas, também chamadas de encargos trabalhistas são contribuições obrigatórias a que estão sujeitos os empregadores, variando de acordo com o ramo de atividade, e, no caso da construção civil, podendo variar até de obra para obra. No estudo em questão, adotou-se o percentual de $126,66 \%$, índice encontrado na planilha de Encargos Sociais (Anexo 07).

9) Material + Mão de obra: Constitui o somatório do item Total de Materiais mais o item Total de Mão de Obra.

Os valores encontrados definem uma média ponderada, podendo conter erros positivos ou negativos, devido às características de cada obra e métodos executivos, entre outros fatores. Todo o processo executivo, durante a consideração desses consumos, foi feito considerando-se condições normais de tempo, temperatura e disponibilidade de materiais, equipamentos, mão de obra e projetos em campo. Qualquer perturbação destes itens torna o valor deste serviço diferente do valor pago em obra.

\subsection{Planilha orçamentária}

A Planilha Orçamentária é o documento onde foram registrados as quantidades de cada serviço e seus custos/preços unitários.

A planilha apresenta, primeiramente, um cabeçalho contendo os dados da obra, como o Tipo de Obra, o Número de Pavimentos, o Tipo de Levantamento e a Cidade onde foram cotados os preços dos insumos.

A Planilha Orçamentária resulta da junção da Planilha de Levantamento Resumo, ou seja, das quantidades levantadas, multiplicadas pelo valor do custo unitário encontrado na Planilha de Composição de Preço Unitário, e é composta de 05 (cinco) colunas contendo as seguintes informações:

1) Rede: especifica o tipo de instalação que está sendo levantada (hidráulica, esgoto ou pluvial);

2) Item: indica a descrição (nome) dos insumos que foram quantificados no levantamento;

3) Quantidade: apresenta o número de repetições de cada item que consta no projeto; 4) Custo Unitário: indicada o preço final (material + mão de obra) encontrado para cada insumo ou serviço na Planilha de Composição de Preço Unitário;

5) Custo Total: trata-se da multiplicação da coluna Quantidade pelo seu Custo Unitário, resultando-se então no custo total de cada insumo/serviço.

\subsection{Planilha cálculo de índice}

Esta planilha tem por objetivo apresentar um índice para o custo de estimativa das instalações hidrossanitárias (água fria, água pluvial e esgotamento sanitário), a partir da área de construção do empreendimento citado. Este índice auxilia na composição de um custo para a instalação hidrossanitária de qualquer empreendimento similar, podendo substituir os orçamentos detalhados em vários momentos (quando há falta de projeto, tempo para execução detalhada, estimativa para custos de viabilidade etc.) de forma eficiente e aproximada.

A planilha apresenta um cabeçalho contendo os dados da obra, Classificação, número de pavimentos, tipo de levantamento, ambientes e a quantidade de peças utilizadas em cada um deles e a Cidade onde foram cotados os preços dos insumos.

O cálculo do índice foi realizado dividindo-se o Valor Total da instalação hidrossanitária dessa obra, encontrado na Planilha Orçamentária, pela área construída, levantada em projeto, e pelo INCC do mês de junho (mês em que foram realizadas as cotações no mercado). Assim, chegou-se ao índice de 0,0515 INCC/ $\mathrm{M}^{2}$ de instalação hidrossanitária, para uma obra comercial com as caraterísticas apresentadas nesse estudo.

Para a utilização deste índice em qualquer outro empreendimento similar, é necessário ter em mãos a área de construção do empreendimento que se deseja estudar e o último INCC apresentado nos sites de índice econômicos brasileiros. Multiplicando o índice citado acima pela área de construção do empreendimento e pelo INCC atual, obtêm-se um valor em reais $(\mathrm{R} \$)$ que pode ser usado como estimativa de custo para uma instalação hidrossanitária (água fria, água pluvial e esgotamento sanitário).

Esta estimativa não leva em consideração a 
interligação das redes internas do empreendimento com as redes da concessionária. Os custos são computados a partir do hidrômetro e até a caixa de passagem de destino final do empreendimento.

Para o mês de apresentação do projeto, o índice foi atualizado e obteve-se o valor final da instalação hidro sanitária reajustado até então.

\section{CONCLUSÃO}

O mercado da Construção Civil, a cada dia, torna-se mais ágil e competitivo, necessitando assim, de informações decisivas, claras e rápidas, que o acompanhem de maneira satisfatória.

A execução de um empreendimento e sua entrega no prazo (em que se incluem todas as suas etapas) costuma ser as principais metas das empresas de construção civil. Assim, o orçamento do empreendimento torna-se cada dia mais importante, e permite fazer avaliações de desempenho físico e financeiro, intervindo de maneira positiva para a melhoria da qualidade, no cumprimento dos prazos e barateamento dos custos.

Observa-se que a empresa da construção civil necessita refletir, urgentemente, sobre a formulação orçamentária, visando, além de atender à demanda, em constante crescimento, garantir sua competitividade no mercado. Dessa forma, os índices da construção e a padronização dos procedimentos de cálculo do preço para as obras viriam a minimizar deficiências verificadas no cálculo, além de agilizá-los.

Para a Engenharia Civil, a possibilidade de poder estimar um orçamento de instalações hidrossanitárias com dados por estimativa, analisados e resultantes de uma metodologia de estudo, mostra a importância dessa área, para compor o orçamento total do empreendimento. Assim, esse índice pode ser apresentado como uma ferramenta para auxiliar o desenvolvimento e planejamento de uma obra.

\section{REFERÊNCIAS}

AGÊNCIA GOIANA DE TRANSPORTES E OBRAS (AGETOP). Critérios e Normas para Orçamento de Obras Civis Utilizados pela Agetop. Goiânia, 2006.

ASSOCIAÇÃO BRASILEIRA DE NORMAS TÉCNICAS (ABNT). NBR 12721: Avaliação de Custos Unitários e Preparo de Orçamento de Construção para Incorporação de Edifício em Condomínio. Rio de Janeiro, 1999.
CORDEIRO, F. R. F. S. Orçamento e Controle de Custos na Construção Civil. Belo Horizonte, 2007, Monografia apresentada ao Curso de Especialização em Construção Civil da Escola de Engenharia UFMG.

LOPES, C. O; LIBRELOTTO, I. L; AVILA, A. V. Orçamento de Obras - Construção Civil. Santa Catarina, 2003.

MINICHIELLO, M. O. Qualidade no Orçamento do Custo Direto de Produção na Construção Civil. Florianópolis, 2007. Monografia apresentada ao Curso de Tecnologia em Gerenciamento de Obras de Edificações centro Federal de Educação Tecnológica de Santa Catarina - Unidade Florianópolis.

MORETHSON, F. S. Orçamento e custos da construção. São Paulo: Hermus, 1999.

MORIEL, E. RODRIGUES, C, A. Métodos orientativos para a utilização de índices de produtividade variável durante o processo de elaboração de orçamentos na construção civil. Barretos, 2008.

OTERO, J. A. Uso de Modelos Paramétricos em Estimativas de Custo para Construções de Edifícios. Pós-Graduação em Engenharia de Produção, Universidade Federal de Santa Catarina. Florianópolis, 2002.

VALENTINI, J. Metodologia para Elaboração de Orçamentos de Obras Civis. Monografia apresentada ao curso de Especialização em Construção Civil da Escola de Engenharia UFMG. Belo Horizonte, 2009. 